\title{
BENTONITE/CHITOSAN BIOCOMPOSITE AS AN ADSORBENT FOR HEXAVALENT CHROMIUM FROM AQUEOUS SOLUTIONS
}

\author{
H. MOUSSOUT, H. AHLAFI ${ }^{\star}$, MY. S. SLIMANI, F. BOUKHLIFI and I. DAOU
}

Laboratoire de Chimie et Biologie Appliquées à l'Environnement, Faculté des Sciences, Université My Ismail, BP 11201-Zitoune, Meknès, 50000, Maroc.

moussouthammou@gmail.com

slimanimyslimane@gmail.com

hahlafi@yahoo.fr

fboukhlifi@gmail.com

*Corresponding Author: hahlafi@yahoo.fr

\section{ABSTRACT}

The present work focuses on the study of the application of abundant and less expensive materials such as chitosan and bentonite/chitosan biocomposite in the removal of hexavalent chromium. Spectroscopic analysis like techniques FTIR, XRD and BET have been used to characterize the adsorbents. The data indicate that the adsorption of chromium proceeds kinetically according to a pseudo-second order model on both samples and the apparent activation energy (Ea) have been measured to be $22.9 \mathrm{~kJ} \cdot \mathrm{mol}^{-1}$ and $84.4 \mathrm{~kJ} \cdot \mathrm{mol}^{-1}$ for chitosan and $5 \% \mathrm{Bt} / \mathrm{CS}$, respectively. The adsorption isotherm experiments show that the adsorption capacity depends on the studied chromium adsorption temperature. It has been found that the data could be well described by the Langmuir as well as the Freundlich models. Thermodynamic parameters (i.e., change in the free energy $\left(\Delta \mathrm{G}^{\circ}\right)$, the enthalpy $\left(\Delta \mathrm{H}^{\circ}\right)$, and the entropy $\left(\Delta S^{\circ}\right)$ have been also, evaluated.

Keywords: chitosan; bentonite; biocomposite; biosorption; chromium.

\section{Council for Innovative Research}

Peer Review Research Publishing System

Journal: Journal of Advances in Chemistry

Vol. 10, No. 6

editorjaconline@gmail.com

www.cirjac.com 


\section{INTRODUCTION}

Currently, the continuing degradation of the environment is a universal concern for humanity. Efforts in various areas of research are being made for its preservation by reducing the concentration of various pollutants. Among these heavy metals are the most harmful to the environment pollutants. View of their importance, they are used in many sectors of industry in the worldwide. For example, chromium compounds are widely used as leader tanning, textile and woodworking [1-3]. Discharges from these industries are often overloaded by the $\mathrm{Cr}(\mathrm{VI})$ which is recognized by its adverse effects on human health, flora and fauna. Chromium mainly occurs in the trivalent and hexavalent oxidation states. $\mathrm{Cr}$ (III) is usually not toxic at low and medium concentrations, whereas $\operatorname{Cr}(\mathrm{VI})$ is highly toxic, a suspected carcinogenic agent, and has negative effect on the nervous system and bone narrow that is highly soluble and mobile in the aquatic environment [4-6].

Several treatment processes such as chemical reduction, precipitation, ion exchange, membrane separation and adsorption have been applied to remove $\mathrm{Cr}(\mathrm{VI})$ from wastewater [7]. During the last decade attention has been given to treatment processes involving adsorption of $\mathrm{Cr}(\mathrm{VI})$ on low-cost materials. Natural zeolite and clay minerals are low-cost materials which exhibit significant cation exchange capacities due to their negatively charged framework structure [8,9]. However, these materials have little affinity for anion groups [10]. The treatment of water and wastewater contaminated with $\mathrm{Cr}(\mathrm{VI})$ using low-cost adsorbents is a feasible process, provided that the adsorbents have received adequate modification. The modification of the negatively charged surface of minerals with cationic surfactants can effectively remove inorganic anions such as hexavalent chromium species and non-polar organic contaminants from solution. The most widely used organic modifiers is a commercial hexadecyltrimethylammonium (HDTMA), cetyltrimethylammonium (CTMA) and their homologues with ahydrophobic alkyl long tail and a hydrophilic quaternary ammonium cation charged part [11-15].However, there are only a few reports on the adsorption of $\mathrm{Cr}(\mathrm{VI})$ by modified clay minerals with chitosan biopolymer [16]. Chitosan, (1,4)-2-amino-2-deoxy- $-\mathrm{D}$-glucan, is a natural polymer easily derived from chitin, mainly by extensive $\mathrm{N}$-deacetylation with alkaline treatment. The importance of chitin and chitosan motivates extensive research undertaken for their industrial and agricultural industrial utilities. In addition, since chitin and its derivative, chitosan are a kind of environment-friendly polymer material, their use as adsorbent is often of primary interest to the scientific community, due to their adsorptive properties.

The aim of the present study is to investigate chromium species biosorption by bentonite modified with natural chitosan (Bt/CS composite). Batch adsorption process has been used to evaluate the maximum adsorption capacity of CS alone and $\mathrm{Bt} / \mathrm{Cs}$ composite. Bentonite (Bt) and chitosan (CS) have been chosen because of their low cost and abundance in nature and are not toxic to human beings. The chitosan used in this work is extracted from shrimp shells collected from the fishmongers of Meknes city in Morocco. The characterization of these samples was done by Fourier transform infrared spectroscopy (FTIR), X-ray diffraction (XRD), MET and BET. The adsorption kinetics, isotherms and thermodynamics parameters for the chromium removal efficiency have been investigated.

\section{Materials and methods}

\subsection{Materials}

The bentonite $(\mathrm{Bt})$ was provided from Rhone Poulenc Company (France). Chitosan was prepared in our laboratory by deacetylation of chitin (see below). Potassium dichromate $\left(\mathrm{K}_{2} \mathrm{Cr}_{2} \mathrm{O}_{7}\right), \mathrm{HCl}$ and $\mathrm{NaOH}$ have been purchased from Aldrich chemicals and specified to be $=99 \%$ purity. Deionised water was used in all experiments.

\subsection{Preparation of Bt/chitosan biocomposite}

Chitosan (CS) with deacetylation degree (DD) of $83 \%$ has been prepared by deacetylation of chitin which is extracted from shrimp shells collected from the fishmongers of Meknes city in Morocco [17]. The deacetylation reaction has been carried out at $\mathrm{T}=120^{\circ} \mathrm{C}$, by treating chitin with a concentrated $\mathrm{NaOH}$ solution $(\mathrm{C}=12 \mathrm{~N})$. The nanocomposite $(5 \% \mathrm{Bt} / \mathrm{CS})$ has been prepared as follows: chitosan solution was prepared by dissolving chitosan in a $5 \%$ (v/v) aqueous acetic acid solution and the resulting solution was stirred vigorously for about $4 \mathrm{~h}$. Before its use the Bt has been swollen in $50 \mathrm{ml}$ of distilled water and sonificated for $15 \mathrm{~min}$. Thereafter, the chitosan solution was slowly added to the Bt suspension at $60{ }^{\circ} \mathrm{C}$. During the mixing process, the weight ratio of clay to chitosan was $5 \% \mathrm{Bt} / \mathrm{CS}$. The reaction mixture has stirred for $24 \mathrm{~h}$, separated by centrifugation and washed with distilled water. Then, the nanocomposite has been dried at $80^{\circ} \mathrm{C}$ for $12 \mathrm{~h}$ and ground to powder.

\subsection{Characterization methods}

Samples of CS and 5\%Bt/CS were prepared for FT-IR, XRD, MEB and BET Analysis: a) XRD patterns were obtained using a X'PERT MPD-PRO wide angle X-ray powder diffractometer operating at $45 \mathrm{kV}$ and $40 \mathrm{~mA}$ with CuK radiation $(\lambda=1,542 \AA)$, b) FTIR spectra have been recorded in absorption frequencies $\left(400-4000 \mathrm{~cm}^{-1}\right)$ in an FTIR (Shimadzu, JASCO 4100). The samples were prepared in $\mathrm{KBr}$ discs from very well dried mixtures of about $4 \%$ (w/w) and stored in a desiccator, c) $\mathrm{N}_{2}$ adsorption measurements at $-196{ }^{\circ} \mathrm{C}$ were performed with a Micromeritics ASAP 2010. The specific surface area and the average pore diameter were determined according to the standard Brunauer, Emmett and Teller (BET) and Barrett, Joyner and Halenda (BJH) methods, respectively. 


\subsection{Adsorption experiments}

Batch experiments have been carried out to evaluate the adsorption capacity of the samples for chromium species. The effect of temperature on the adsorption of chromium by CS and $5 \% \mathrm{Bt} / \mathrm{CS}$ was studied at $\mathrm{T}=298,308$ and $318 \mathrm{~K}$. A mass $\mathrm{m}$ of the adsorbent was mixed with $20 \mathrm{ml}$ of an aqueous solution of $\mathrm{K}_{2} \mathrm{Cr}_{2} \mathrm{O}_{7}$ with initial concentration $\mathrm{C}_{0}$ $(\mathrm{mol} / \mathrm{l})$. The mixture has then been stirred for a period "t" at constant $\mathrm{pH}=5$. After the adsorption time, the solid is separated from the solution by filtration through $0.45 \mu \mathrm{m}$ Millipore nylon filter. The chromium concentration in the aqueous phase has been analysed by UV-VIS spectrophotometer (Schimadzu Mini 4100) at $350 \mathrm{~nm}$. The removed amount of chromium from the aqueous solution was calculated by the following equation:

$$
q e=V \cdot \frac{(C i-C e)}{m}
$$

Where qe is the removed amount of chromium, from the liquid phase $(\mathrm{mg} / \mathrm{g})$. Ci and Ce are the initial and residual concentrations in $\mathrm{mg} / \mathrm{l}$, respectively; $\mathrm{V}$ is the volume of liquid phase $(\mathrm{L})$ and $\mathrm{m}$ is the mass of the sorbent $(\mathrm{mg})$.

\section{EXPERIMENTAL RESULTS}

\subsection{Adsorbent characterization}

\subsubsection{FTIR characterization}

FTIR spectra of natural chitosan, Bentonite and 5\%Bt/CS are shown in Fig. 1 and compared with each other. The bands at $3452 \mathrm{~cm}^{-1}$ and the shoulder at $3225 \mathrm{~cm}^{-1}$ are attributed to the $\mathrm{O}-\mathrm{H}$ and $\mathrm{N}-\mathrm{H}$ stretching vibrations and water hydrogen bonded to other water molecules within the interlayer [18], respectively. The characteristic bands in the region $900-1200 \mathrm{~cm}^{-1}$ are attributed to different types of Si-O and Si-O-Si stretching vibrations. Additional bands between 450 and $900 \mathrm{~cm}^{-1}$ in the spectrum of Bt have been assigned to typical Si-O and Si-O-Al bending modes [19]. The appearance of new bands located at $2850 \mathrm{~cm}^{-1}$ and $2925 \mathrm{~cm}^{-1}$ in the spectrum of $5 \% \mathrm{Bt} / \mathrm{CS}$ sample can be noted. These bands are related to the symmetric and asymmetric stretching vibration of $\mathrm{CH}_{2}$ and $\mathrm{CH}_{3}$ which give two bending vibrations located at 1463 and $1474 \mathrm{~cm}^{-1}$, due to the methylene scissoring modes. The presence of these $\mathrm{C}-\mathrm{H}$ vibrations suggest that the composition of the modified $\mathrm{Bt}$ in the interlayer space may have resulted from ion exchange of $\mathrm{Na}^{+}$with the quaternary ammonium cation in chitosan [16, 20]. The bands assigned to the stretching vibrations of C-O-C linkages in the polysaccharide structure appear at $1155 \mathrm{~cm}^{-1}, 1085 \mathrm{~cm}^{-1}$ and $1025 \mathrm{~cm}^{-1}$ is the antisymmetric stretching of C-O-C bridge. The bands observed between 1700 and $1250 \mathrm{~cm}^{-1}$ are characteristic of chitosan and have been reported to be the amide I and II bands. Similar results have been reported by other authors using bentonite or other clays [19-21].

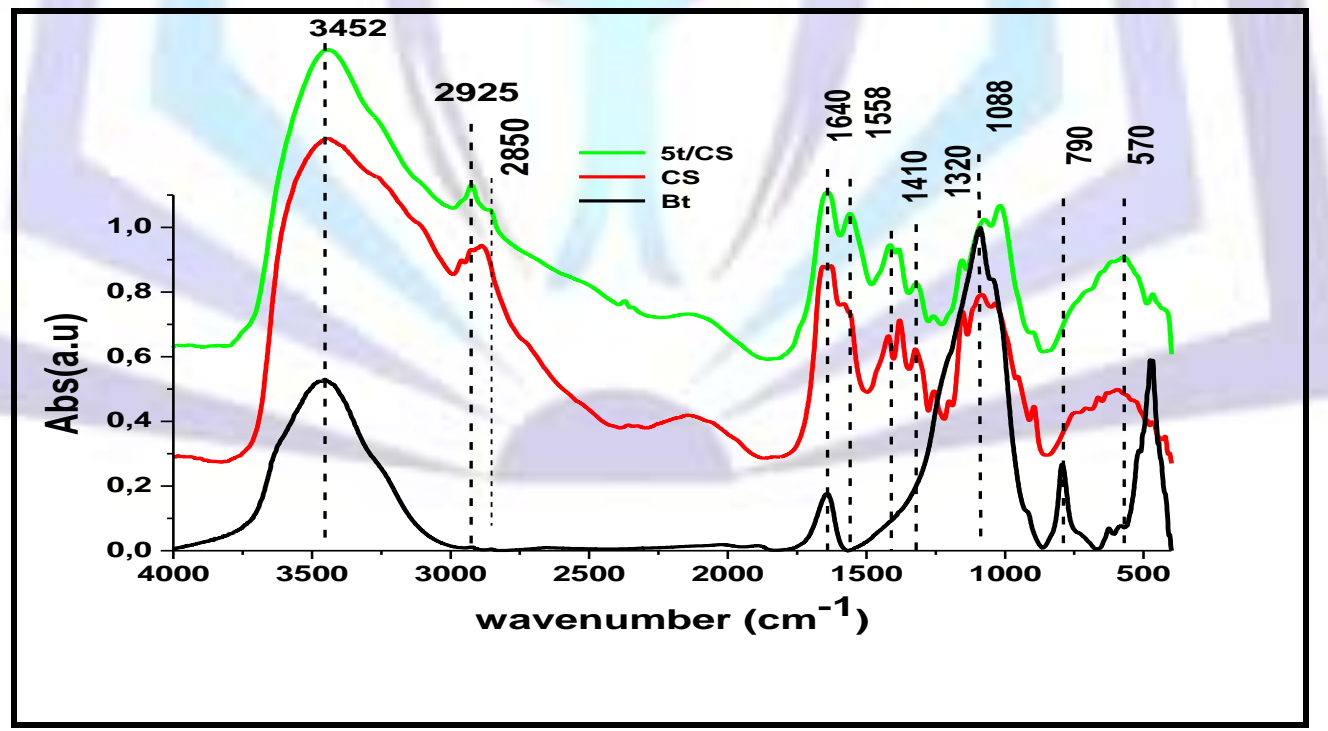

Fig 1: FTIR spectra ofchitosan andbiocomposite $5 \% \mathrm{Bt} / \mathrm{CS}$

\subsubsection{XRD Analysis of CS, Bt and $5 \% \mathrm{Bt} / \mathrm{CS}$}

Fig. 2 illustrates the XRD patterns of Bt, CS and $5 \% \mathrm{Bt} / \mathrm{CS}$. The formation of the intercalated/exfoliated structure of the composite $5 \% \mathrm{Bt} / \mathrm{CS}$ is confirmed by the disappearance of the peak at $2 \theta^{\circ}$ value corresponding to a basal spacing of $\mathrm{d}(001)=14.92 \AA$ in $\mathrm{Bt}$. The higher $\mathrm{d}(001)$ value obtained for the biocomposite is related to the chitosan chains which enter in the lamellar space of $\mathrm{Bt}$ and exfoliate the silicate layers [22,23]. For chitosan, two main diffraction peaks at $2 \theta^{\circ}=9.28$ and 4.57 are observed. The broadened peak around $2 \theta^{\circ}=9.28$ indicates the existence of an amorphous structure. After 
being formed into the biocomposite, these two crystalline peaks still exist, but their positions have been moved from the initial values of $2 \theta^{\circ}$ and become somewhat stronger and sharper. The result suggests a higher crystallinity or denser packing in the main chain in comparison with the neat chitosan. This result is consistent with other reports in the literatures $[24,25]$. It is evident that the addition of Bt greatly changed the crystallinity of chitosan, confirming the strong interaction between chitosan and Bt leading to the exfoliation of Bt scheets.

\subsubsection{BET surface area}

In order to investigate the effect of Bt exfoliation on the pore structure of $5 \% \mathrm{Bt} / \mathrm{CS}$ biocomposite, $\mathrm{N}_{2}$ adsorption isotherms have measured and the isotherms are presented in Fig.3. It is interesting to note that a type IV adsorption isotherm is exhibited in all samples with $\mathrm{H} 3$ type hysteresis loops according to the original IUPAC classification [26], implying that the samples mainly contain mesopores and macropores. The results show that the BET surface area of Bt $\left(37.8 \mathrm{~m}^{2} / \mathrm{g}\right)$ decreases to $0.6 \mathrm{~m}^{2} / \mathrm{g}$ when it's modified with chitosan biopolymer which has longer carbon chain, and the pore volume decreases also from 0.1005 to $0.0026 \mathrm{~cm}^{3} / \mathrm{g}$. The decease of surface area and the pores volume may be attributed to exchange sites which are satisfied by chitosan with large molecular size resulting in inaccessibility of the internal surface to nitrogen gas and the blocking of the pores in the $5 \% \mathrm{Bt} / \mathrm{CS}$. The pore-size distribution calculated from the BJH desorption isotherm are inserted in Figure 3. The pore-size distribution centers around $100 \AA$ for $B t$ and $140 \AA$ for $5 \% \mathrm{Bt} / \mathrm{CS}$ indicate a mesoporous structures of the samples. This is in accordance with the conclusions drawn in the literatures [27-29].

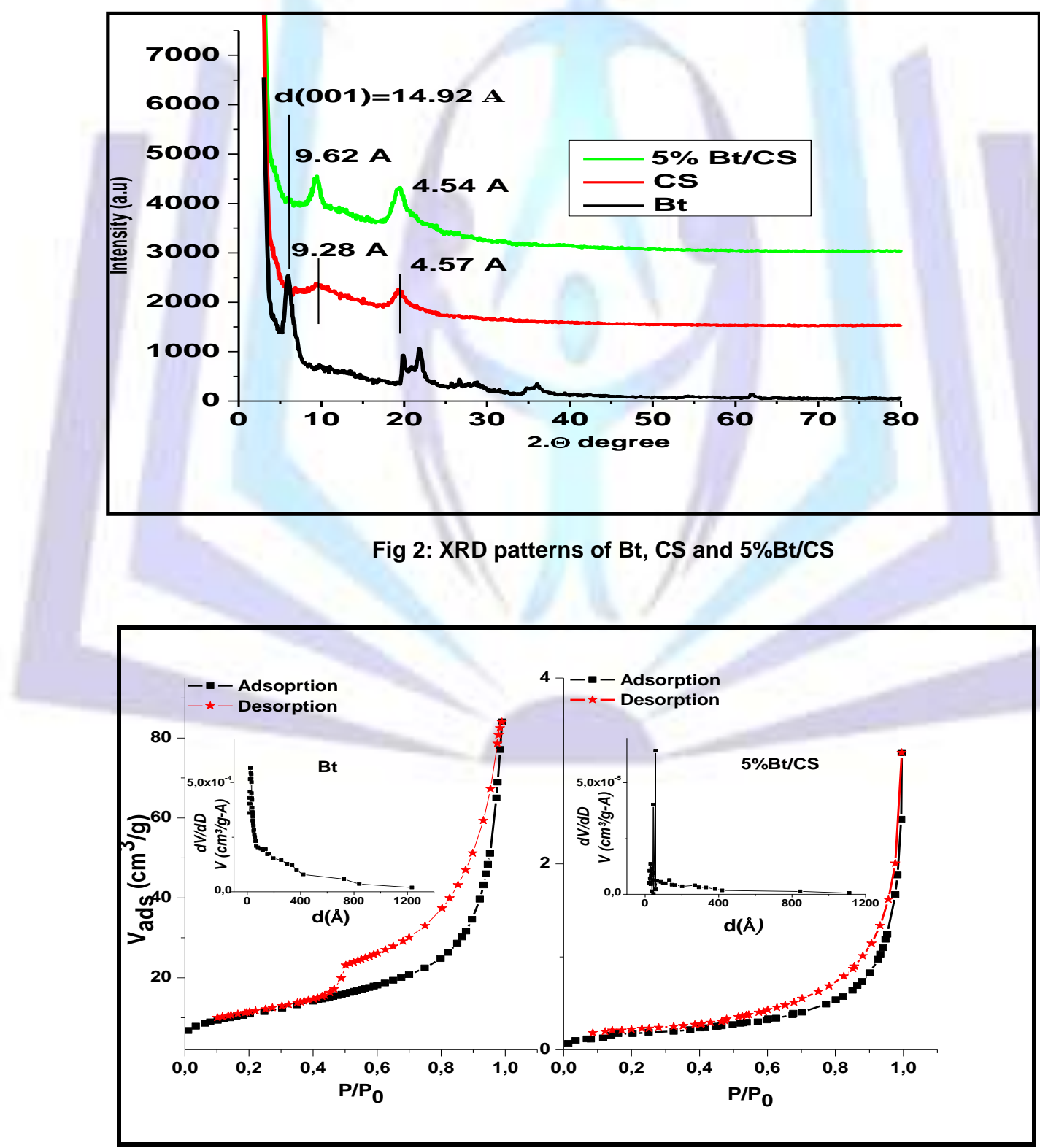

Fig 3: $\mathrm{N}_{2}$ adsorption/desorption isotherms of $\mathrm{Bt}$ and $5 \% \mathrm{Bt} / \mathrm{CS}$ 


\subsection{Chromium removal studies}

\subsubsection{Adsorption kinetics}

The plots of qe versus $t$ at different temperatures of $\mathrm{Cr}(\mathrm{VI})$ adsorption onto $\mathrm{CS}$ and $5 \% \mathrm{Bt} / \mathrm{CS}$ carried out at $\mathrm{pH}=5$ are shown inFig 4. It has been found that $\mathrm{Cr}(\mathrm{VI})$ adsorption rate is relatively fast for the first 40 min with the plateau occurring at approximately $80 \mathrm{~min}$ for both samples. The data reveal that the adsorption uptake qe $(\mathrm{mg} / \mathrm{g})$ decreases with increased adsorption temperature and the adsorption rate declines and reaches the equilibrium position over time. The amounts of chromium adsorbed at equilibrium are $58 \mathrm{mg} / \mathrm{g}$ and $59 \mathrm{mg} / \mathrm{g}$, , for chitosan and $5 \%$ Bt/CS, respectively. These quantities are mainly due to the adsorption of chromium onto the chitosan.

The kinetic data have been evaluated using the Lageregen, first order [30, 31] and Ho et coll [32, 33] pseudo second order kinetic equations. The equations corresponding to the above models are given in table 1 . The kinetic constants can be obtained from the plot of $\log (q e-q)(F i g .5 A)$ and t/qe(Fig.5B) against different time intervals, for the three temperatures considered in the adsorption of chromium onto CS and $5 \% \mathrm{Bt} / \mathrm{CS}$. As it is shown in the table 1 , the equilibrium adsorption capacity (qe) obtained experimentally correlates better with the second order kinetic model. The regression coefficient obtained from this model is higher (Table 1), thereby leading to the conclusion that the experimental data fit well with the second order kinetics.

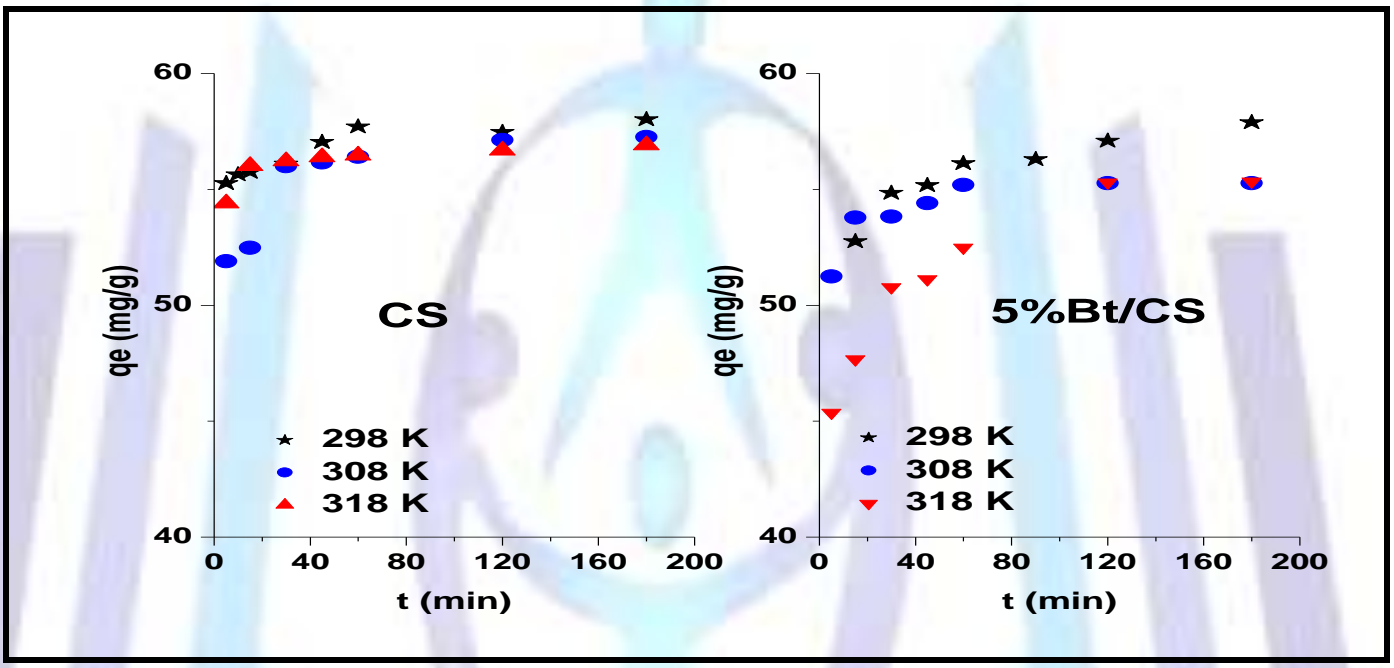

Fig 4: Effect of the contact time on adsorption capacity of CS and 5\%Bt/CS for $\mathrm{Cr}(\mathrm{VI})$ atdifferent temperatures $\mathrm{C}_{0}(\mathrm{Cr}(\mathrm{VI}))=10^{-3} \mathrm{~mol} / \mathrm{l}$.

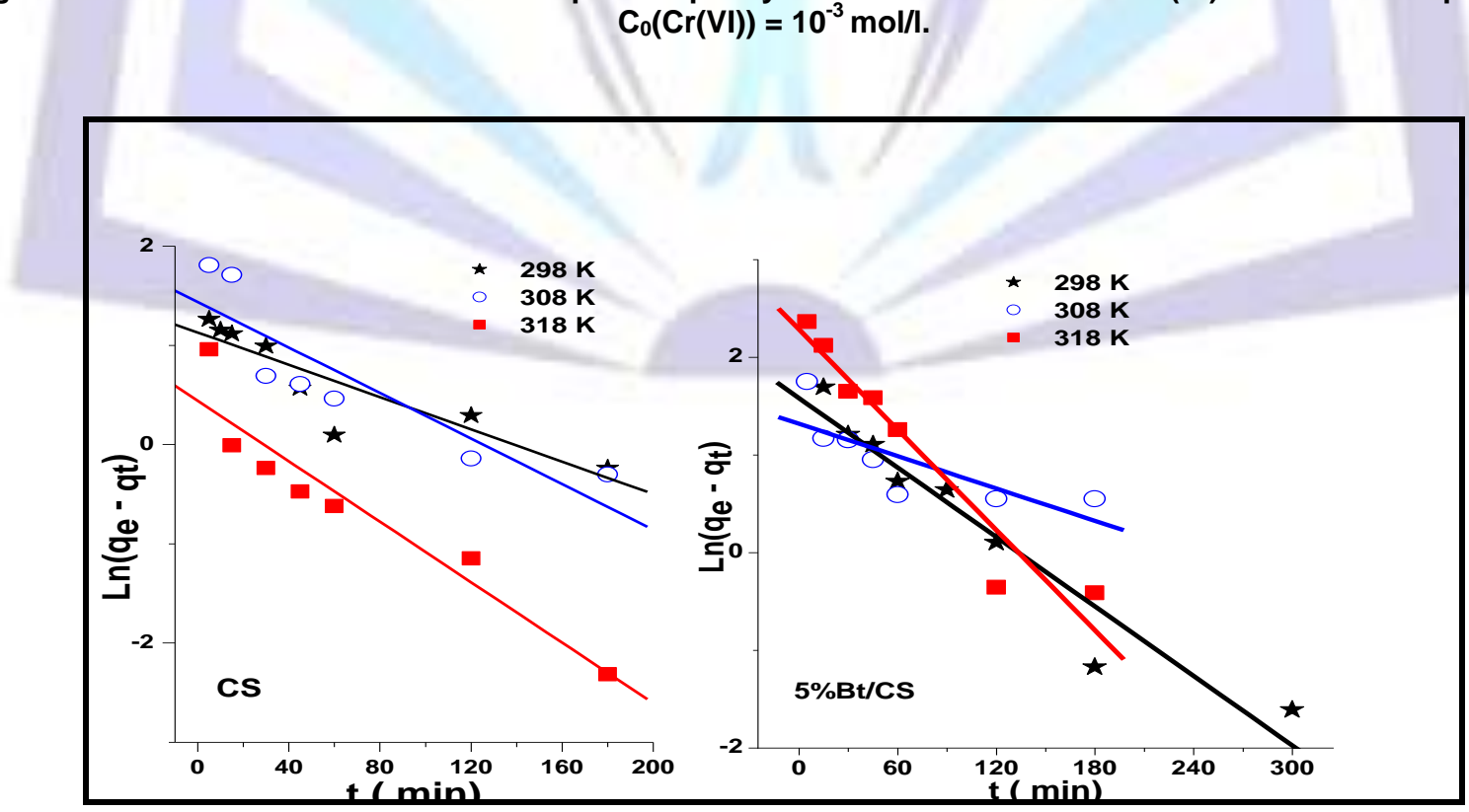

Fig 5A: Adsorption kinetics fitted by pseudo-first order equation for retention of $\mathrm{Cr}(\mathrm{VI})$ on $\mathrm{CS}$ and $5 \% \mathrm{Bt} / \mathrm{CS}$ at different temperatures 


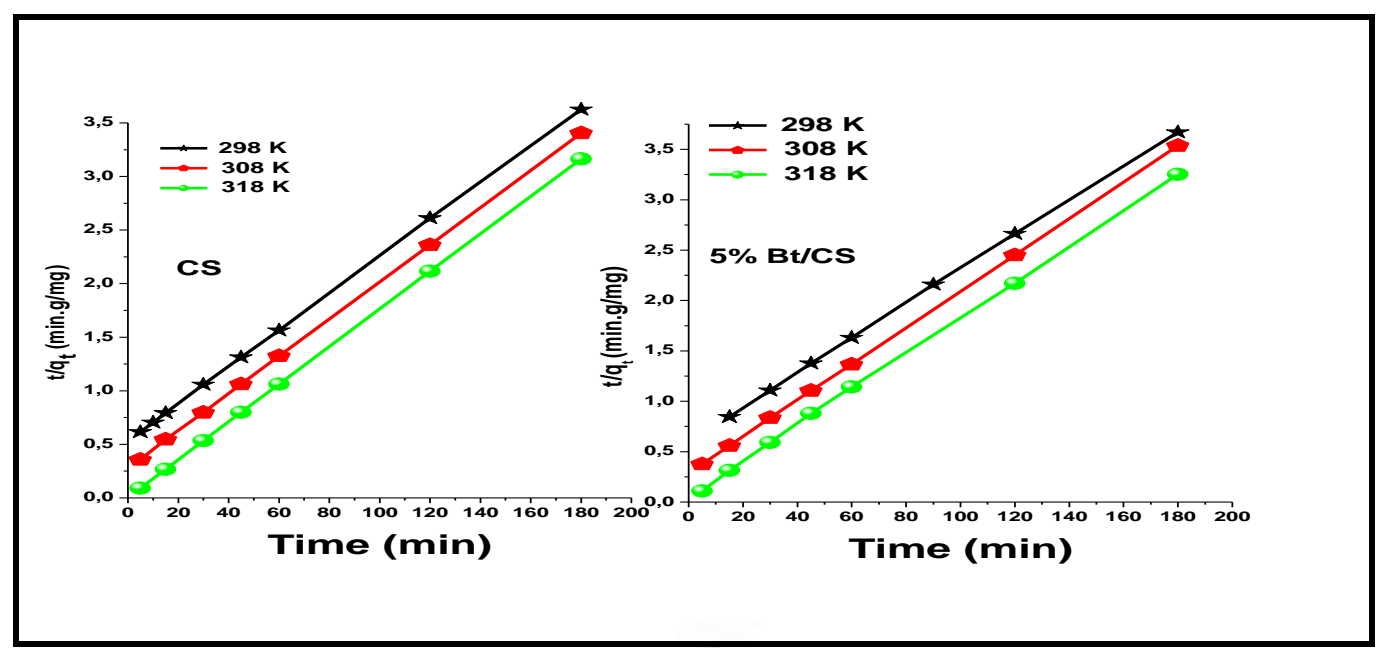

Fig 5B: Adsorption kinetics fitted by pseudo-second order equation for retention of $\mathrm{Cr}(\mathrm{VI})$ on $\mathrm{CS}$ and $5 \% \mathrm{Bt} / \mathrm{CS}$ at different temperatures

Table 1. Kinetic parameters for the adsorption of $\mathrm{Cr}(\mathrm{VI})$ on $\mathrm{CS}$ and $5 \% \mathrm{Bt} / \mathrm{CS}$.

\begin{tabular}{|c|c|c|c|c|c|c|c|c|}
\hline \multirow[b]{3}{*}{ Adsorbent } & \multirow[b]{3}{*}{$\begin{array}{c}q_{\text {Exp }} \\
(m g / g)\end{array}$} & \multirow[b]{3}{*}{$\mathbf{T}(\mathrm{K})$} & \multicolumn{3}{|c|}{ Lagergren (pseudo $1^{\text {st }}$ order) } & \multicolumn{3}{|c|}{ Ho et coll (pseudo $2^{\text {nd }}$ order) } \\
\hline & & & $\log \left(q_{e}-0\right.$ & $\log q_{e}$ & $\frac{K_{1}}{2.303} t$ & $\frac{t}{q_{t}}=$ & $\frac{1}{2 \cdot q_{e}}-\frac{1}{q_{e}} t$ & \\
\hline & & & $k_{1}\left(\min ^{-1}\right)$ & $\begin{array}{l}q_{\text {eq }} \text { cal } \\
(m g / g)\end{array}$ & $R_{1}^{2}$ & $k_{2}(g / m g \cdot m i n)$ & $q_{e q}$ cal $(m g / g)$ & $\mathbf{R}_{2}^{2}$ \\
\hline \multirow{3}{*}{ ఓ } & 58.20 & 298 & $8.14 \times 10^{-3}$ & 3.10 & 0.896 & $2.74 \times 10^{-2}$ & 58.07 & 0.999 \\
\hline & 58.04 & 308 & $1.14 \times 10^{-2}$ & 4.21 & 0.885 & $3.35 \times 10^{-2}$ & 57.57 & 0.999 \\
\hline & 57.12 & 318 & $1.15 \times 10^{-2}$ & 1.55 & 0.951 & $4.89 \times 10^{-2}$ & 56.94 & 1 \\
\hline \multirow{3}{*}{ 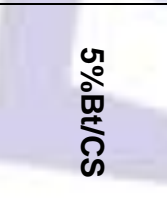 } & 58.15 & 298 & $1.18 \times 10^{-2}$ & 4.86 & 0.965 & $7.41 \times 10^{-3}$ & 58.44 & 0.999 \\
\hline & 57.07 & 308 & $5.52 \times 10^{-3}$ & 3.73 & 0.788 & $3.09 \times 10^{-2}$ & 55.46 & 0.999 \\
\hline & 56.01 & 318 & $1.71 \times 10^{-2}$ & 9.82 & 0.963 & $6.26 \times 10^{-2}$ & 56.21 & 0.999 \\
\hline
\end{tabular}

\subsubsection{Adsorption activation energy}

The magnitude of the activation energy is commonly used as the basis for differentiating between physical and chemical adsorption. The pseudo second order rate constants of chromium adsorption onto CS and $5 \% \mathrm{CS} / \mathrm{Bt}$ is expressed as a function of temperature by Arrhenius equation: $\ln \left(k_{2}\right)=\ln A-E a / R . T$

where $k_{2}$ is the rate constant of the pseudo second order (g/mg.min), Ea the activation energy of sorption ( $\left.\mathrm{kJ} \cdot \mathrm{mol}^{-1}\right), \mathrm{R}$ the universal gas constant $\left(8.314 \mathrm{~J} . \mathrm{mol}^{-1} \mathrm{~K}\right)$ and $\mathrm{T}$ the solution temperature $(\mathrm{K})$.

A plot of Ink $\mathrm{K}_{2}$ versus $1 / \mathrm{T}$ yields a straight line, with slope $-\mathrm{Ea} / \mathrm{R}$ (Fig. 6). The activation energy for $\mathrm{Cr}(\mathrm{VI})$ adsorption onto $\mathrm{CS}$ is found equal to be $22.9 \mathrm{~kJ}_{\mathrm{mol}}^{-1}$ and $84.4 \mathrm{~kJ} . \mathrm{mol}^{-1}$ for that of chromium adsorption onto $5 \% \mathrm{Bt} / \mathrm{CS}$, suggesting that the $\mathrm{Cr}(\mathrm{VI})$ is physically adsorbed onto $\mathrm{CS}$ and chemically adsorbed onto the $5 \% \mathrm{Bt} / \mathrm{CS}$ sample. It is known that when activation energy is low, the rate is controlled by intra-particle diffusion mechanism, which is a physical step in the adsorption process. 


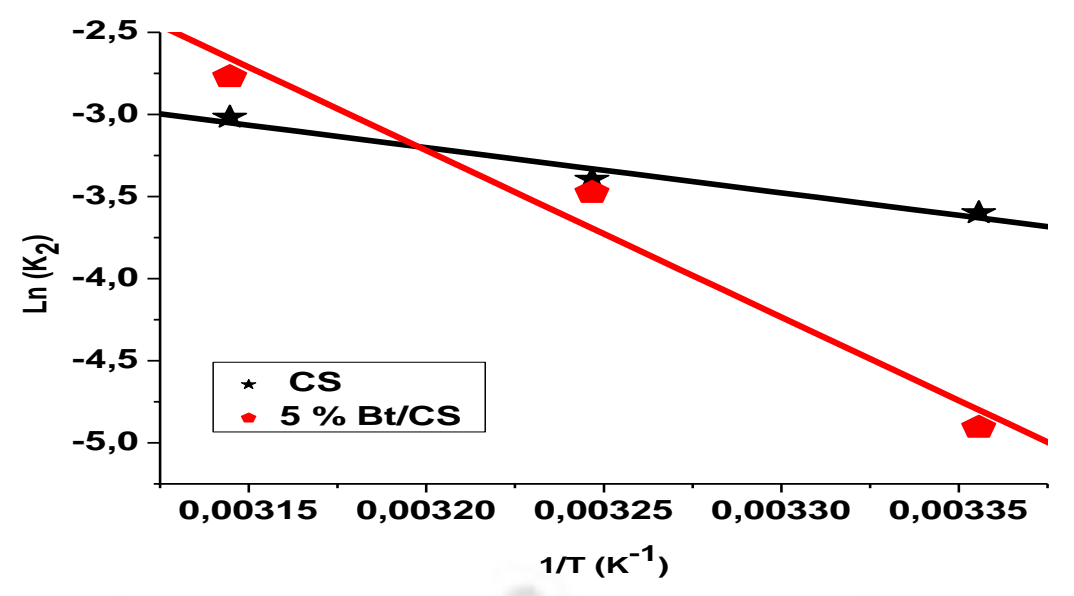

Fig 6: Arrhenius plot of $\ln \mathrm{K}_{2}$ vs 1/T

\subsubsection{Adsorption isotherms}

The sorption isotherms of chromium on CS and 5\%Bt/CS at various temperatures are presented in Fig. 7. The amounts of chromium adsorbed on $5 \% \mathrm{Bt} / \mathrm{CS}$ increase slightly by increasing the temperature, while in the case of CS, the temperature has a negative effect. This may be due to a decrease in the degree of freedom of adsorbed species and a decrease in number of active sites or to a desorption of physically adsorbed chromium on chitosan when the adsorption temperature is increased. The $\mathrm{Cr}(\mathrm{VI})$ adsorption uptake has beenfound to decrease with an increase in solution temperature for all initial concentration. This indicates that the adsorption reaction of $\mathrm{Cr}(\mathrm{VI})$ on $\mathrm{CS}$ is exothermic.

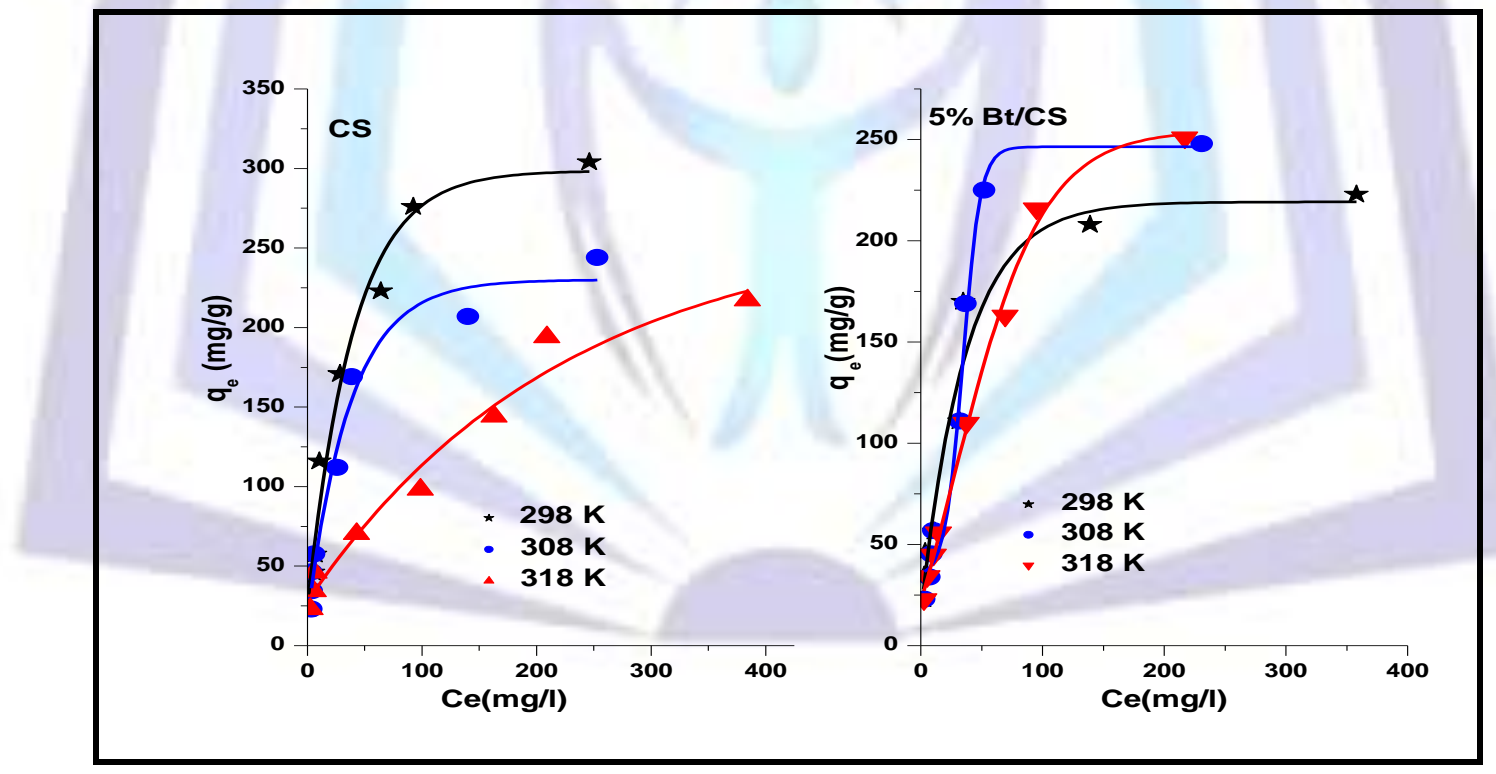

Fig 7: Effect on the $\mathrm{Cr}(\mathrm{VI})$ concentration on adsorption capacity of $\mathrm{CS}$ and $5 \% \mathrm{Bt} / \mathrm{CS}$ at various $\mathrm{T}$

The experimental sorption data are fitted according to two models, Freundlich adsorption model and Langmuir adsorption model:

\section{- Langmuir model:}

The expression of this model is: $q e=\frac{q m \cdot K_{L} \cdot C e}{1+K_{L} \cdot C e}$

where qe is the equilibrium $\mathrm{Cr}(\mathrm{VI})$ concentration on adsorbent $(\mathrm{mg} / \mathrm{g})$, Ce is the equilibrium $\mathrm{Cr}(\mathrm{VI})$ concentration in solution (mg/L), $\mathrm{Qm}$ is the monolayer capacity of the adsorbent $(\mathrm{mg} / \mathrm{g})$ and $\mathrm{K}$ is the Langmuir adsorption constant (L/mg). 
The Langmuir equation is applicable to homogeneous sorption where the sorption of each sorbate molecule onto the surface has equal sorption activation energy.

- Freundlich isotherm:

The Freundlich isotherm is an empirical equation which can be used for non ideal sorption that involves heterogeneous sorption. The Freundlich isotherm is commonly given by the followingequation:

$$
q e=K_{F} \cdot C_{e}^{1 / n}
$$

whereqeis the equilibrium concentration on adsorbent $(\mathrm{mg} / \mathrm{g}), \mathrm{Ce}$ is the equilibrium concentration in solution (mg/L), $\mathrm{K}_{\mathrm{F}}(\mathrm{mg} / \mathrm{g})$ and $1 / \mathrm{n}$ are the Freundlich constants characteristic of the system indicators of adsorption capacity and adsorption intensity, respectively.

The values of $\mathrm{qm}, \mathrm{K}_{\mathrm{L}}, \mathrm{K}_{\mathrm{F}}, 1 / \mathrm{n}$ and the correlation coefficients are given in Table 2 where it is shown that $R^{2}$ values obtained for Langmuir isotherm model are generally higher than those obtained by the Freundlich model. Nevertheless, the values of $n$ ranged between $0<1 / n<1$ in the Freundlich model for various temperatures demonstrated that the adsorption of $\mathrm{Cr}(\mathrm{VI})$ on these adsorbents is also favourable. These are also consistent with the results in the adsorption kinetics. If the values of $K_{F}$ and $1 / n$ are compared at all the studied temperatures, the results indicate that higher values of $1 / \mathrm{n}$ and lower values of $\mathrm{K}_{\mathrm{F}}$ have been obtained at higher temperatures.

Table 2. Isotherm constants for $\mathrm{Cr}(\mathrm{VI})$ adsorption onto $\mathrm{CS}$ and $5 \% \mathrm{Bt} / \mathrm{CS}$.

\begin{tabular}{|c|c|c|c|c|c|c|c|}
\hline \multirow{2}{*}{ Sample } & \multirow{2}{*}{$\mathrm{T}(\mathrm{K})$} & \multicolumn{3}{|c|}{ Langmuir } & \multicolumn{3}{c|}{ Freundlich } \\
\cline { 2 - 8 } & & $\mathrm{R}^{2}$ & $\mathrm{~K}_{\mathrm{L}}(\mathrm{L} / \mathrm{mg})$ & $\mathrm{Q}_{\mathrm{m}}(\mathrm{mg} / \mathrm{g})$ & $\mathrm{R}^{2}$ & $1 / \mathrm{n}$ & $\mathrm{K}_{\mathrm{F}}(\mathrm{mg} / \mathrm{g})$ \\
\hline \multirow{3}{*}{$\mathrm{CS}$} & 298 & 0.987 & 0.028 & 395.25 & 0.953 & 0.484 & 27.571 \\
\cline { 2 - 8 } & 308 & 0.960 & 0.026 & 331.12 & 0.955 & 0.509 & 18.324 \\
\cline { 2 - 8 } & 318 & 0.984 & 0.068 & 151.97 & 0.986 & 0.421 & 17.498 \\
\hline \multirow{3}{*}{$5 \%$ Bt/CS } & 298 & 0.972 & 0.07 & 187.97 & 0.957 & 0.446 & 21.90 \\
\cline { 2 - 8 } & 308 & 0.963 & 0.04 & 190.11 & 0.952 & 0.625 & 12.69 \\
\cline { 2 - 8 } & 318 & 0.969 & 0.09 & 151.06 & 0.992 & 0.585 & 12.50 \\
\hline
\end{tabular}

\subsubsection{Thermodynamic studies}

The thermodynamic parameters such as standard free energy $\left(\Delta G^{0}\right)$, standard enthalpy $\left(\Delta H^{0}\right)$ and the standard entropy $\left(\Delta S^{0}\right)$ changes have been calculated from the adsorption studies at different temperatures. These parameters are obtained from the equations below, and the graph shown in Fig.8:

with: $\Delta G^{\circ}=-R T I n K c$,

where $\mathrm{R}$ is the gas constant $\left(\mathrm{kJmol}^{-1} \mathrm{~K}^{-1}\right), \mathrm{T}$ is the temperature $(\mathrm{K})$, and $\mathrm{K}_{\mathrm{c}}$ is the distribution coefficient defined as the ratio of the amount adsorbed (qe in $\mathrm{mg} / \mathrm{g}$ ) to the equilibrium concentration $(\mathrm{Ce}$ in $\mathrm{mg} / \mathrm{l})$ : $\mathrm{Kc}=\mathrm{q}_{\mathrm{e}} / \mathrm{C}_{\mathrm{e}}$.

The Gibbs free energy change is also related to enthalpy change $\left(\Delta \mathrm{H}^{\circ}\right)$ and entropy change $\left(\Delta \mathrm{S}^{\circ}\right)$ at constant temperature by the following equation: $\quad \operatorname{lnK} c=\frac{\Delta S^{\circ}}{\mathrm{R}}-\frac{\Delta \mathrm{H}^{\circ}}{\mathrm{R} . \mathrm{T}}$

The values of $\Delta \mathrm{H}^{\circ}$ and $\Delta \mathrm{S}^{\circ}$ have been obtained from the slope and intercept of the linear plot of $\ln (\mathrm{Kc})$ versus $1 / \mathrm{T}$ (Fig. 8). Thenegative values of $\Delta \mathrm{G}^{\circ}($ Table 3$)$ indicate that the adsorption process was favourable and spontaneous in nature. The negative value of $\Delta \mathrm{H}^{\circ}$ suggests that the adsorption is exothermic and the positive value confirm the endothermic process. The positive value of $\Delta S^{\circ}$ shows increase randomness at the solid-solution interface during the adsorption of chromium onto $5 \% \mathrm{Bt} / \mathrm{CS}$ and reflects the affinity of the adsorbent for $\mathrm{Cr}(\mathrm{VI})$. 


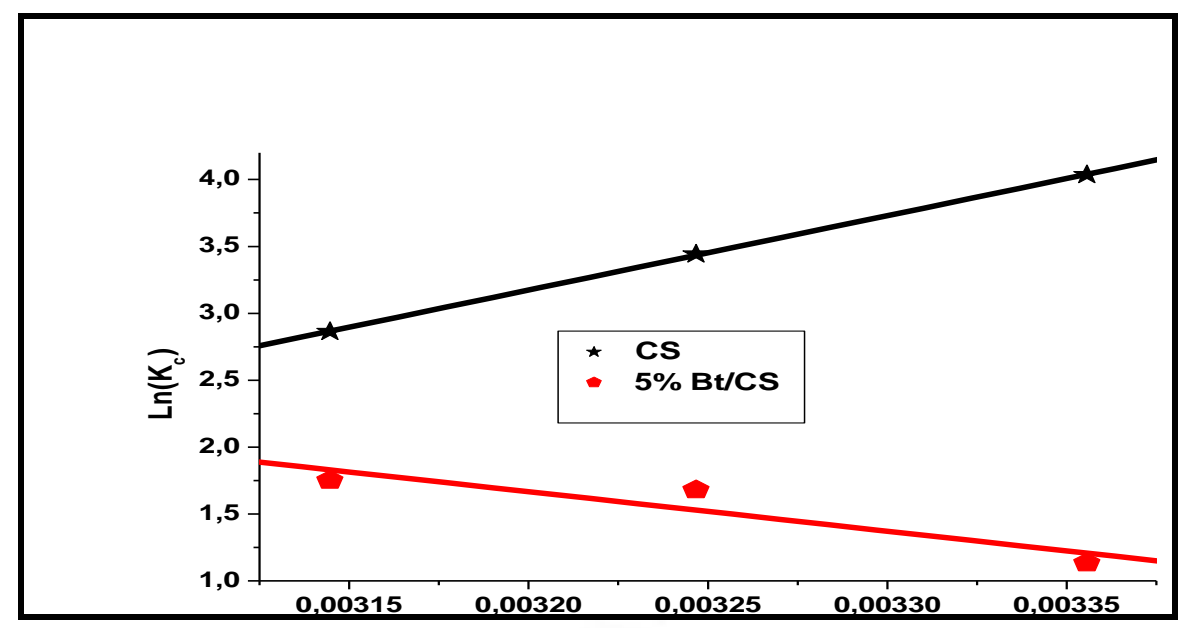

Fig 8: Van't Hoff plot for estimating thermodynamic parameters

Table 3: Thermodynamic parameters for the adsorption of $\mathrm{Cr}(\mathrm{VI})$ onto $\mathrm{CS}$ and $5 \% \mathrm{Bt} / \mathrm{CS}$

\begin{tabular}{|c|c|c|c|c|c|}
\hline Sample & $\mathbf{T}(\mathbf{K})$ & $\Delta \mathrm{G}^{0}\left(\mathrm{KJ} . \mathrm{mol}^{-1}\right)$ & $\Delta \mathrm{S}^{0}\left(\mathrm{~J} . \mathrm{mol}^{-1} \cdot \mathrm{K}^{-1}\right)$ & $\Delta \mathrm{H}^{0}\left(\mathrm{KJ} . \mathrm{mol}^{-1}\right)$ & $\mathbf{R}^{2}$ \\
\hline \multirow{3}{*}{ CS } & 298 & -9.99 & \multirow{3}{*}{ - 46.18} & \multirow{3}{*}{ - 121.41} & \multirow{3}{*}{0.988} \\
\hline & 308 & -8.81 & & & \\
\hline & 318 & -7.57 & & & \\
\hline \multirow{3}{*}{$5 \% B t / C S$} & 298 & -2.81 & \multirow{3}{*}{92.40} & \multirow{3}{*}{24.54} & \multirow{3}{*}{0.922} \\
\hline & 308 & -4.30 & & & \\
\hline & 318 & -4.63 & & & \\
\hline
\end{tabular}

\section{CONCLUSIONS}

$\mathrm{Bt} / \mathrm{CS}$ biocomposite has prepared from the raw materials and used as a biosorbent for the removal of chromium ion from aqueous solution. FTIR, XRD and surface area measurement clearly shows that the chitosan biopolymer entered into the interlayer space of the bentonite. Adsorption of $\mathrm{Cr}(\mathrm{VI})$ on $\mathrm{CS}$ and $5 \% \mathrm{Bt} / \mathrm{CS}$ can be considered as a simple, fast and economic method for its removal from water and wastewater. A very good agreement with the obtained experimental data indicates that a pseudo-second-order kinetic model is favorable for chromium ion adsorption on these samples. The activation parameters of the adsorption process helped in the prediction of how the adsorption of chromium ions might vary with temperature changes. The activation energy, Ea, is $22.9 \mathrm{~kJ} . \mathrm{mol}^{-1}$ and $84.4 \mathrm{~kJ} . \mathrm{mol}^{-1}$, respectively for chromium adsorption onto CS and 5\%Bt/CS. The Langmuir and Freundlich isotherms models, has provided the best fit for experimental data. The maximum monolayer adsorption capacity of $\mathrm{CS}$ and $5 \% \mathrm{Bt} / \mathrm{CS}$ adsorbents as obtained from Langmuir adsorption isotherms has been found to be 395.25 and $187.97 \mathrm{mg} / \mathrm{g}$, respectively, for $\mathrm{Cr}(\mathrm{VI})$ at $\mathrm{pH}=5$. The thermodynamic analysis confirms the spontaneous character of adsorption process. The decrease in randomness of species, has resulted with negative value of $\Delta \mathrm{S}^{\circ}$. Therefore, chitosan and $5 \% \mathrm{Bt} / \mathrm{CS}$ could be used as adsorbent for $\mathrm{Cu}(\mathrm{VI})$ removal from wastewater.

\section{REFERENCES}

[1] K.M.S. Sumathi, S. Mahimairaja, R. Naidu, 2005. Bioresource Technology 96, 309.

[2] Benjamin A. Rybicki, C. Cole Johnson, J. Uman, and Jay M. Gore1l, 1993. Movement Disorders 8, 87.

[3] C. B. Sekomo, D. P.L. Rousseau, Saleh A. Saleh, Piet N.L. Lens,2012. Ecological Engineering 44,102.

[4] A. J Chaudhary, B. Ganguli and S. M Grimes, 2002. J. of Chemical Technology and Biotechnology 77, 767.

[5] Joel Barnhart, 1997. Journal of Soil Contamination 6, 561.

[6] D. E. Stilwell, K. D. Gorny, 1997. Bull. Environ. Contam. Toxicol. 58, 22.

[7] Yue Wen, Zhiru Tang, Yi Chen, YuexiaGu, 2011. Chemical Engineering Journal 175, 110.

[8] SufiaHena, 2010. Journal of Hazardous Materials 181, 474. 
[9] B. Voleskyand Z. R. Holan, 1995. Biotechnol. Prog. 11, 235.

[10] Z. Djedidi, M. Bouda, Med Aly Souissi, R. Ben Cheikh, G. Mercier, R. DayalTyagi, Jean-François Blais, 2009. J. of Hazardous Materials 172, 1372.

[11] M. Abdollahi, M. Rezaei, G. Farzi, 2012.Journal of Food Engineering 111, 343.

[12] Max Hetzer, Daniel De Kee, 2008.chemical engineering research and design 8 6, 1083.

[13] Kin-takLau, Chong Gu, David Hui, 2006. Composites: Part B 37, 425.

[14] S.F. Wang, L. Shen, Y.J. Tong, L. Chen, I.Y. Phang, P.Q. Lim, T.X. Liu, 2005. Polymer Degradation and Stability 90, 123.

[15] E. Günister, D. Pestreli, Cüneyt H. Ünlü, OyaAtıcı, NurferGüngör, 2007. Carbohydrate Polymers 67, 358.

[16] S. Pandey, S.B. Mishra, 2011. Journal of Colloid and Interface Science 361, 509-520.

[17] H. Ahlafi, H. Moussout, F. Boukhlifi, M. Echetna, M. Naciri B. and S. My Slimane, 2013. Mediterranean Journal of Chemistry 2 (2013) 503.

[18] HuaiguoXue and al., 2007. Biosensors and Bioelectronics 22, 816.

[19] Jian-Mei Li, 2009. Bioresource Technology 100, 1168.

[20] Ping Yin and al., 2011. Materials Chemistry and Physics 129, 168- 175.

[21] John Nguyen and al., 2013. Carbohydrate Polymers 97, 587.

[22] K. Zhang et al., 2009. Polymer Degradation and Stability 94, 2121.

[23] M. Darder et al., 2005. Applied Clay Science 28,199-208.

[24] Tang et al. Polymer Degradation and Stability 94 (2009) 124-131.

[25] Wang SF, Chen L, Tong YJ., 2006. J Polym Sci. Part A PolymChem 44, 686.

[26] K.S.W. Sing and al. , 1985. Pure Appl. Chem. 57, 603.

[27] Y. Xi et al., 2010. Applied Clay Science 48,92.

[28] S. E. Burns and al., 2006. Journal of Geotechnical and Geoenvironmental Engineering 132, 1404.

[29] HONGPING HE AND AL., 2006. Clays and Clay Minerals 54, 689.

[30] M. Alkan, M. Dogan, Y. Turhan, Ö. Demirbas, P. Turan, 2008. Chemical Engineering Journal 139, 213.

[31] M. Monier, D.M. Ayad, A.A. Sarhan, 2010. Journal of Hazardous Materials 176, 348.

[32] Limin Zhou, YipingWang, Zhirong Liu, Qunwu Huang, 2009. Journal of Hazardous Materials 161, 995.

[33] Yuh-Shan Ho, 2006. Journal of Hazardous Materials B136, 681. 